Article

\title{
Relative Income and Life Satisfaction among Chinese Adults
}

\author{
Chenghua Guan ${ }^{1,2}$, Yingjie Qiu $1,2, * \mathbb{C}$ and Ruopeng $\mathrm{An}^{3}$ \\ 1 School of Economics and Resource Management, Beijing Normal University, Beijing 100875, China; \\ guanchenghua@bnu.edu.cn \\ 2 Center for Innovation and Development Studies, Beijing Normal University (Zhuhai), Zhuhai 519087, China \\ 3 Brown School, Washington University in St. Louis, MO 63130, USA; ruopeng@wustl.edu \\ * Correspondence: qyj_goalkeeper@163.com
}

Received: 20 August 2019; Accepted: 11 October 2019; Published: 14 October 2019

check for updates

\begin{abstract}
Life satisfaction is a key component of people's subjective well-being. This study assessed the relationship between relative income and life satisfaction among Chinese adults, using data from a cross-sectional survey. Individual-level data $(\mathrm{N}=1369)$ came from the 2016 China Genuine Progress indicator Survey (CGPiS) conducted in Beijing and Chengdu, China. Ordered logistic regressions were performed to examine the relationship between relative income and life satisfaction among CGPiS adult respondents. Respondents' life satisfaction was positively associated with relative income in comparison to their relatives and friends but not associated with relative income in comparison to their residing community and city. Subgroup analyses replicated the findings among male respondents and respondents with good or excellent self-rated health. In contrast, female respondents' life satisfaction was positively associated with relative income in comparison to their city of residence, but not associated with relative income in comparison to their relatives, friends, and residing community. Life satisfaction among those with poor or fair self-rated health was not associated with any of the four dimensions of relative income. Relative income in comparison to relatives and friends was positively associated with life satisfaction in Chinese adults. Future studies adopting a longitudinal or experimental design are warranted to replicate the findings.
\end{abstract}

Keywords: relative income; life satisfaction; subjective well-being; Chinese

\section{Introduction}

The respective role of relative income and absolute income in determining people's life satisfaction has profound implications for policy making, which constantly faces the challenge of balancing considerations of equity and efficiency. Aimed at improving life satisfaction in the general population, and especially among the poor, should less-developed nations focus more on economic growth as a way to increase people's absolute income? Similarly, should wealthy nations focus more on income redistribution to reduce relative income inequality? Theories provide little guidance regarding the specific cutoff for a nation's income level. Since theories provide little guidance regarding the specific cutoff for a nation's income level, answers to these questions largely depend upon empirical evidence from country-specific analysis.

The general idea is that people compare themselves against a range of criteria. Satisfaction is then judged by the gap between their actual situation and the baseline. The person being compared can be other relevant people, such as relatives, neighbors, and friends. This study aimed to assess the relationship between relative income and life satisfaction among Chinese adults. We fielded a cross-sectional survey in two of the largest cities in China, which included questions about respondents' self-assessments of how their life satisfaction compared to different geographic and non-geographic 
reference groups. The survey measured respondents' absolute and relative income, and the latter was constructed through comparison to four distinct domains of one's social network. China is a particularly interesting case. Because it is not only the world's most populous country but also a nation that has witnessed a very rapid increase in income inequality during its transition from a socialist planned economy to a market-based system. In this paper, we try to answer these questions with empirical evidence from China and attempt to address the potential impact of the findings on public policies in China.

The strengths of this study include (1) new data from the economic and social survey in China, to provide new evidence on the impact of income comparisons among Chinese; (2) refined measures on relative income, to assess the four domains of relative income in comparison to respondents' relatives, friends, residing community, and residing city in relation to life satisfaction; and (3) subsample analyses stratified by gender and health status, to identify the potential heterogeneities in the relationship between relative income and life satisfaction across population subgroups.

\section{Literature Review}

Existing definitions of happiness, subjective well-being, life satisfaction, and quality of life suggest a conceptual overlap between these constructs. However, a related study showed that high positive correlations between happiness, subjective well-being, psychological, and health domains of quality of life, life satisfaction, and positive affect [1]. Actually, subjective well-being refers to an individual's overall assessment of the quality of life from his or her own perspective [2]. Conventional measures for subjective well-being primarily focused on the tangible aspects of living conditions, such as housing and employment $[3,4]$, whereas more recent research starts to explore the less tangible parts of subjective well-being, namely what people think and feel about their lives, such as the quality of their relationships, their emotions and resilience, and their overall life satisfaction. As a key component of subjective well-being, life satisfaction is one's evaluation of life as a whole, rather than the feelings and emotions that are experienced in the moment.

Early studies on life satisfaction were conducted within the domains of psychology and philosophy and focused on the individual-level determinants of life satisfaction, such as genes, personalities, and value systems [5-7]. Human health is increasingly recognized as "a state of complete physical, mental, and social well-being and not merely the absence of disease or infirmity" [8]. Subsequently, life satisfaction, as an important dimension of human well-being, has attracted attention from a variety of research disciplines including public health, economics, sociology, education, and policy. An extensive set of demographic and socioeconomic factors, such as employment, religion, health status, educational attainment, social network, and income, were documented to be associated with life satisfaction [9-15].

The relationship between income and life satisfaction could be complex. Conventional economic theory predicts an increase in life satisfaction (also known as "utility" in economics terminology) attributable to people's ability to purchase and consume more goods given a higher disposable income [16]. Indeed, empirical evidence from less developed nations documented higher life satisfaction in response to economic growth, but such a positive relationship between income and life satisfaction was not replicated in the wealthy nations $[17,18]$. These contradicting observations led to the Easterlin Paradox-an increase in personal income can significantly increase happiness and life satisfaction; when income level is low, happiness or life satisfaction is initially positively influenced by income both across and within nations, whereas life satisfaction is simply less dependent income as one's wealth increases [19].

The relative income hypothesis posits that the satisfaction or utility a person derives from a given income depends on its relative magnitude in the society rather than its absolute amount [16]. This hypothesis might hold the potential to explain, at least in part, the Easterlin Paradox-as people's living condition continues to improve, relative income could play a more essential role in determining life satisfaction relative to absolute income. A handful of recent studies assessed the influence of relative income on people's life satisfaction, independent of their absolute income level. The majority 
reported a positive relationship between relative income and life satisfaction [13,20-24]. However, these studies defined relative income in a single dimension.

Measures on relative income can be largely classified into two major categories: (1) an objective measure, such as absolute income level relative to the median or average income of an individual's community, city, state/province, or country of residence, or of an individual's gender, age, or education group $[13,20,22,25]$, and (2) a subjective measure, such as self-perceived relative income level in comparison to a reference group [21,23,24,26-31]. This study adopted a subjective relative income measure and further refined it by making a contrast with four different dimensions of one's social network.

There is not much direct evidence to date about those whom people really compare themselves to. Most of the time, the evidence for comparison is indirect. This is because surveys usually do not contain direct questions about the composition of reference groups. Previous studies have usually defined reference groups based on geographical location or demographic characteristics. However, other social reference groups that have frequent social contact with individuals, such as relatives and friends, may be more prominent. In addition, previous studies have not systematically studied which geographic aggregation level has the greatest influence on life satisfaction. Residents of the same community or city may be a particularly important reference groups.

Some papers have defined the reference group as the inhabitants of the geographical area where the respondent lives [32-34]. Certain authors defined reference groups as being composed of people with whom one has daily interactions, such as friends and colleagues [35-37]. Only a few studies have identified different social dimensions of relative income at the same time [38-40]. None of the above studies assessed the potential mediating and/or moderating effect from certain personal characteristics, most prominently, gender and health status. The relative importance attached to a specific reference group may differ between men and women in income comparisons, partially due to the historical and enduring division of labor between genders [41]. As for the less healthy individuals, they could be more concerned about their health status than other things [42].

This paper is one of the latest studies that try not only to provide direct evidence of comparisons but also to assess the relative impact of various types of comparisons, including different geographic and non-geographic reference groups among Chinese adults. It also tries to identify the potential heterogeneities in the relationship between relative income and life satisfaction across population subgroups and address the potential impact of the findings on public policies in China.

The potential influence path of relative income on life satisfaction is Social Comparison Theory. Individuals naturally compare themselves with others who are similar to them, rather than those with significantly higher or lower income levels [43]. Individuals crave the sense of identity that comes from being different from others. They tend to focus on differences with other similar individuals. Such comparison will improve life satisfaction of those individuals with relatively high income levels because it will lead to a stronger social identity [44]. Therefore, comparing with reference groups with different degrees of similarity may lead to different effects.

We hypothesized that relative income would be positively associated with Chinese adults' life satisfaction after adjusting for their absolute income level and other demographic and socioeconomic factors. The effect of relative income of relatives, friends, residing community, and residing city on life satisfaction would be distinct.

\section{Methods}

\subsection{Survey Setting and Participants}

Conducted by Beijing Normal University (BNU) and cooperated with China Household Finance Survey (CHFS) in 2016, the China Genuine Progress indicator Survey (CGPiS) aimed to evaluate China's economic and social development. The CGPiS covered a variety of topics, such as family structure, employment, income and wealth, household expenditure, life satisfaction, and volunteer 
services. In-person interviews were conducted with household members (both adolescents aged 12 to 17 years and adults aged 18 years and above) residing in Beijing and Chengdu, two of the largest cities in China. Detailed information regarding the CGPiS sampling design and questionnaires can be requested from BNU. The CGPiS was approved by the BNU Institutional Review Board. This study used completely de-identified CGPiS data and was exempt from ethical approval. Among the 1863 adult CGPiS participants who answered the question items pertaining to relative income, 494 had missing values for the outcome and/or covariates and were, therefore, excluded from the analyses. The final sample included 1369 respondents.

\subsection{Life Satisfaction}

The question pertaining to life satisfaction was adapted from the World Values Survey, "People's satisfaction with life varies. All things considered, how satisfied are you with your life as a whole these days?" Respondents were asked to rate their satisfaction with life using a 1-5 scale from being completely dissatisfied to being completely satisfied.

\subsection{Relative Income}

Relative income was self-perceived by the respondents. Relative income was measured in four dimensions in comparison to respondents' relatives, friends, residing community, and residing city. The four questions were, "Compare your personal income over the past year to your relatives (alternatively, your friends, residents in your community, or residents in your city), would you say that your personal income is much lower (coded as one), somewhat lower (coded as two), about the same (coded as three), somewhat higher (coded as four), or much higher (coded as five) than your peers"?

\subsection{Covariates}

The following individual characteristics were adjusted for in the regression analyses: a continuous variable for age in years; a dichotomous variable for sex (female, with male in the reference group); a dichotomous variable for ethnicity (non-Han, with Han in the reference group); a dichotomous variable for marital status (married, with divorced, separated, widowed, and never married in the reference group); a count variable for the number of children in a household; a dichotomous variable for self-rated health (good or excellent self-rated health, with poor or fair self-rated health in the reference group); a three-class categorical variable for education level (high school, above high school, with below high school in the reference group); a continuous variable for the natural logarithmic absolute annual income; a dichotomous variable for job type (government employment, with non-government employment in the reference group); a dichotomous variable for religion (being religious, with being nonreligious in the reference group); and a dichotomous variable for resident registration status (local residence, with non-local residence in the reference group).

\subsection{Statistical Analyses}

Ordered logistic regressions were performed to examine the relationship between the four dimensions of relative income and life satisfaction among CGPiS adult participants. The regressions were conducted on the entire sample as well as on subsamples stratified by sex (males and females) and respondents' self-rated health status (good/excellent self-rated health and poor/fair self-rated health). The dependent variable was an ordinal variable denoting a respondent's current level of life satisfaction ranging from one (completely dissatisfied) to five (completely satisfied). The four key independent variables were the four dimensions of relative income in comparison to respondents' relatives, friends, residing community, and residing city. All regressions adjusted for all the aforementioned covariates, including age, sex, ethnicity, marital status, number of children in the household, self-rated health, education level, natural logarithmic absolute annual income, job type, religion, and resident registration status. We tested the proportional odds assumption using a likelihood ratio test. The test statistic is not significant ( $p$-value $>0.05$ ), indicating a lack of violation from the proportional odds assumption. 
All statistical procedures were performed in Stata 15.1 SE version (StataCorp, College Station, TX, USA).

\subsection{Sensitivity Analysis}

Two streams of sensitivity analyses were performed to assess the robustness of modeling results with respect to each key independent variables and analytic sample. In the first stream of sensitivity analyses, a sensitivity analysis was performed to assess the robustness of modeling results with respect to missing variable values. We performed multiple imputations to impute the missing values for the outcome variable and covariates. Specifically, the iterative Markov chain Monte Carlo (MCMC) method was applied to impute missing values, based on the multivariate normal regression where the variables with missing values served as the dependent variables and the remaining variables with complete data served as the independent variables. A total of 100 imputations were generated. We used Stata 15.1 SE version (StataCorp, College Station, TX, USA) multiple imputations functions, including "mi xtset", "mi register", "mi impute", and "mi estimate". The modeling results based on the imputed full dataset $(\mathrm{N}=1863)$ were nearly identical to those obtained from the regressions that did not use multiple imputations. In the second stream of sensitivity analyses, we performed the analysis for each social reference group, and the modeling results for each specific group were nearly identical to those obtained from the regressions that included all reference groups. We thus decided to exclusively report the modeling results from the original regressions.

\section{Results}

Table 1 reports the study sample characteristics. The average life satisfaction scored 3.5 among CGPiS adult participants. Respondents' relative income in comparison to their relatives, friends, residing community, and residing city scored 2.5, 2.3, 2.6, and 2.0, respectively. Approximately 56\% of them were male, and $8 \%$ were with poor or fair self-rated health. Annual absolute income among survey participants averaged 24,000 RMB. Approximately $42 \%$ had lower than high school education, $29 \%$ had high school, and $29 \%$ had higher than high school education. Respondents averaged 42 years of age and had an average of 1.2 children in the household. Approximately $4 \%$ were non-Han, 95\% were married, $11 \%$ were government employees, $8 \%$ were religious, and $76 \%$ were registered local residents in Beijing and Chengdu.

Table 1. Individual Characteristics of the 2016 CGPiS Adult Sample.

\begin{tabular}{|c|c|c|c|c|c|}
\hline Individual Characteristics & $\begin{array}{c}\text { Entire } \\
\text { Sample }\end{array}$ & Male & Female & $\begin{array}{c}\text { Good or } \\
\text { Excellent } \\
\text { Health }\end{array}$ & $\begin{array}{l}\text { Poor or Fair } \\
\text { Health }\end{array}$ \\
\hline Sample size & 1369 & 769 & 600 & 1257 & 112 \\
\hline \multicolumn{6}{|l|}{ Satisfaction with life (1-5) (mean) } \\
\hline Satisfaction with life & $3.50(0.70)$ & $3.48(0.71)$ & $3.52(0.69)$ & $3.52(0.69)$ & $3.26(0.80)$ \\
\hline \multicolumn{6}{|l|}{ Relative income (1-5) (mean) } \\
\hline Residing community & $2.56(0.89)$ & $2.61(0.91)$ & $2.50(0.87)$ & $2.60(0.89)$ & $2.16(0.88)$ \\
\hline Residing city & $2.04(0.99)$ & $2.12(1.04)$ & $1.94(0.92)$ & $2.07(1.00)$ & $1.68(0.85)$ \\
\hline \multicolumn{6}{|l|}{ Age (mean) } \\
\hline Age in years & $42.38(9.72)$ & $43.69(9.90)$ & $40.70(9.23)$ & $42.30(9.74)$ & $43.26(9.48)$ \\
\hline \multicolumn{6}{|l|}{$\operatorname{Sex}(\%)$} \\
\hline Male & $0.56(0.50)$ & & & $0.57(0.50)$ & $0.48(0.50)$ \\
\hline \multicolumn{6}{|l|}{ Marital status (\%) } \\
\hline Married & $0.95(0.21)$ & $0.96(0.20)$ & $0.95(0.21)$ & $0.96(0.20)$ & $0.94(0.24)$ \\
\hline
\end{tabular}


Table 1. Cont.

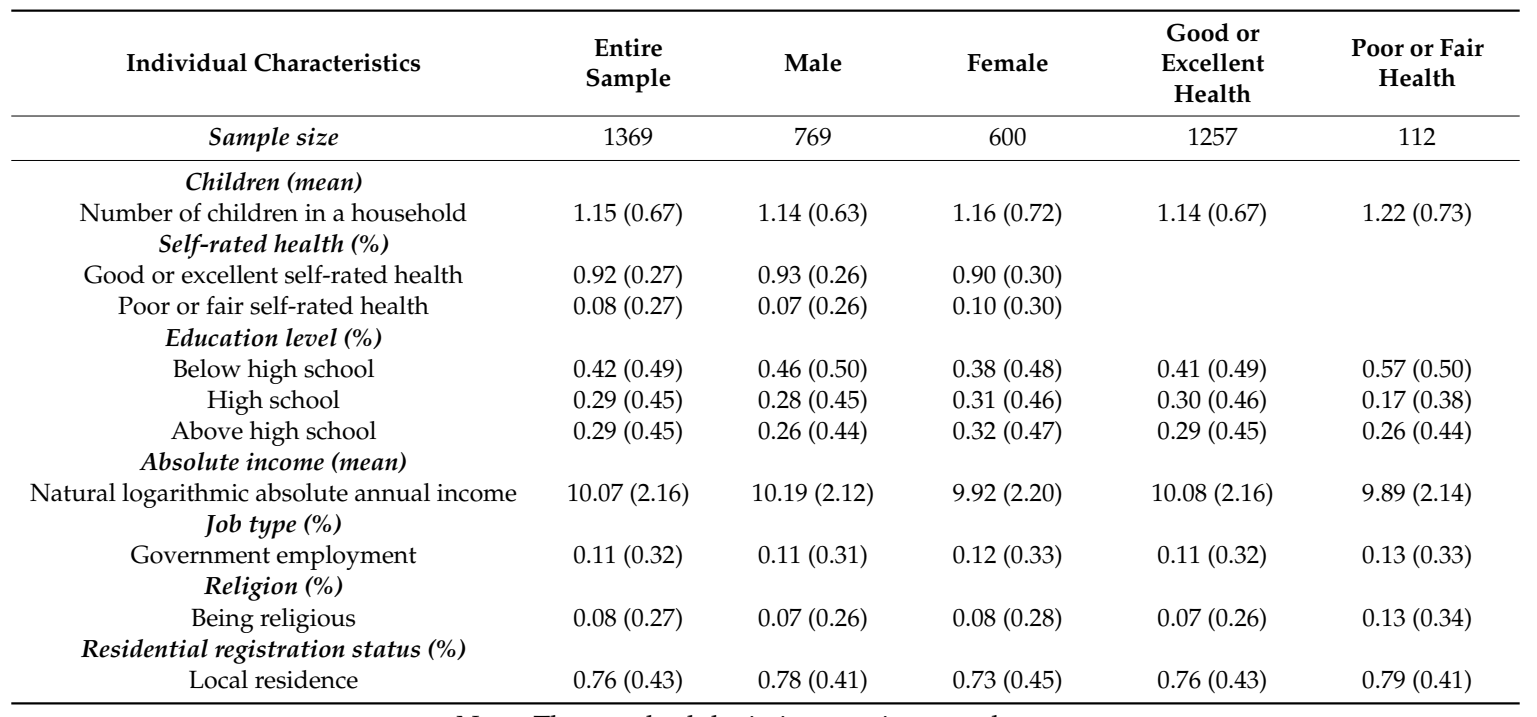

Note: The standard deviations are in parentheses.

Table 2 reports the estimated odds ratios from the ordered logistic regression based on the entire sample. Respondents' life satisfaction was found to be positively associated with their relative income in comparison to relatives and friends but not associated with their relative income in comparison to residing community and city. A one-unit increase in the respondents' relative income in comparison to their relatives and friends was associated with an increase in the odds of being in a higher level of life satisfaction by $20 \%$ (odds ratio $[\mathrm{OR}]=1.20 ; 95 \%$ confidence interval $[\mathrm{CI}]=1.03,1.38 ; p$-value $<0.05$ ) and $30 \%(\mathrm{OR}=1.30 ; 95 \% \mathrm{CI}=1.11,1.53 ; p$-value $<0.01)$, respectively. In contrast, the estimated odds ratios of respondents' relative income with respect to their residing community and city were statistically non-significant ( $p$-values $>0.05$ ).

Table 3 reports the results from subgroup analyses by sex and self-rated health status. Male respondents' life satisfaction was found to be positively associated with their relative income in comparison to relatives and friends. A one-unit increase in male respondents' relative income in comparison to their relatives and friends was associated with an increase in the odds of being in a higher level of life satisfaction by $22 \%(\mathrm{OR}=1.22 ; 95 \% \mathrm{CI}=1.01,1.47)$ and $44 \%(\mathrm{OR}=1.44 ; 95 \% \mathrm{CI}=1.17,1.78)$, respectively. In contrast, female respondents' life satisfaction was found to be positively associated with their relative income in comparison to residing city. A one-unit increase in female respondents' relative income in comparison to their residing city was associated with an increase in the odds of being in a higher level of life satisfaction by $28 \%(\mathrm{OR}=1.28 ; 95 \% \mathrm{CI}=1.02,1.61)$. Life satisfaction among those who were in good or excellent self-rated health was found to be positively associated with their relative income in comparison to relatives and friends. A one-unit increase in those respondents' relative income in comparison to their relatives and friends was associated with an increase in the odds of being in a higher level of life satisfaction by $20 \%(\mathrm{OR}=1.20 ; 95 \% \mathrm{CI}=1.03,1.39)$ and $28 \%$ $(\mathrm{OR}=1.28 ; 95 \% \mathrm{CI}=1.08,1.52)$, respectively. In contrast, life satisfaction among those who were in poor or fair self-rated health was not found to be associated with any of the four relative income dimensions. Regression coefficients were compared across subgroups using the seemingly unrelated estimation. A statistically significant difference in coefficients was only identified in the respondents' relative income in comparison to their residing city between men and women. 
Table 2. Estimated odds ratios from ordered logistic regression.

\begin{tabular}{|c|c|}
\hline Independent Variable & Odds Ratio $(95 \% \mathrm{CI})$ \\
\hline \multicolumn{2}{|l|}{ Relative income } \\
\hline Relatives & $1.20 *(1.03,1.38)$ \\
\hline Friends & $1.30 * *(1.11,1.53)$ \\
\hline Residing community & $1.09(0.94,1.27)$ \\
\hline Residing city & $1.02(0.89,1.17)$ \\
\hline \multicolumn{2}{|l|}{ Age } \\
\hline Age in years & $1.01(1.00,1.02)$ \\
\hline \multicolumn{2}{|l|}{ Sex } \\
\hline Male & Reference \\
\hline Female & $1.21(0.97,1.51)$ \\
\hline \multicolumn{2}{|l|}{ Ethnicity } \\
\hline Han & Reference \\
\hline Non-Han & $1.90 *(1.11,3.25)$ \\
\hline \multicolumn{2}{|l|}{ Marital status } \\
\hline Divorced or separated or widowed, and never married & Reference \\
\hline Married & $1.85 *(1.06,3.22)$ \\
\hline \multicolumn{2}{|l|}{ Children } \\
\hline Number of children in a household & $1.08(0.91,1.29)$ \\
\hline \multicolumn{2}{|l|}{ Self-rated health } \\
\hline Poor or fair self-rated health & Reference \\
\hline Good or excellent self-rated health & $1.55 *(1.02,2.35)$ \\
\hline \multicolumn{2}{|l|}{ Education level } \\
\hline Below high school & Reference \\
\hline High school & $1.77^{* * *}(1.35,2.32)$ \\
\hline Above high school & $1.55 *(1.11,2.18)$ \\
\hline \multicolumn{2}{|l|}{ Absolute income } \\
\hline Natural logarithmic absolute annual income & $1.07 *(1.02,1.13)$ \\
\hline \multicolumn{2}{|l|}{ Job type } \\
\hline Non-government employment & Reference \\
\hline Government employment & $1.86^{* *}(1.31,2.66)$ \\
\hline \multicolumn{2}{|l|}{ Religion } \\
\hline Being nonreligious & Reference \\
\hline Being religious & $1.12(0.74,1.71)$ \\
\hline \multicolumn{2}{|l|}{ Residential registration status } \\
\hline Non-local residence & Reference \\
\hline Local residence & $1.15(0.88,1.51)$ \\
\hline
\end{tabular}

Notes: Individual-level data $(\mathrm{N}=1369)$ were retrieved from the 2016 China Genuine Progress indicator Survey $(\mathrm{CGPiS}){ }^{*} 0.01 \leq p<0.05,{ }^{* *} 0.001 \leq p<0.01$, and ${ }^{* * *} p<0.001$.

Table 3. Estimated Relationships between Relative Income and Life Satisfaction by Gender and Health Subgroups.

\begin{tabular}{|c|c|c|c|c|c|}
\hline Relative Income & $\begin{array}{c}\text { Entire Sample (N } \\
=1369)\end{array}$ & Male $(N=769)$ & Female $(N=600)$ & $\begin{array}{l}\text { Good or Excellent } \\
\text { Health }(N=1257)\end{array}$ & $\begin{array}{c}\text { Poor or Fair } \\
\text { Health }(N=112)\end{array}$ \\
\hline Relatives & $1.20 *(1.03,1.38)$ & $1.22 *(1.01,1.47)$ & $1.15(0.91,1.45)$ & $1.20 *(1.03,1.39)$ & $1.21(0.68,2.16)$ \\
\hline$p$-value of suest test & & \multicolumn{2}{|c|}{0.73} & \multicolumn{2}{|c|}{0.97} \\
\hline Friends & $1.30 * *(1.11,1.53)$ & $1.44 * *(1.17,1.78)$ & $1.08(0.84,1.40)$ & $1.28^{* *}(1.08,1.52)$ & $1.55(0.87,2.76)$ \\
\hline$p$-value of suest test & & \multicolumn{2}{|c|}{0.12} & \multicolumn{2}{|c|}{0.57} \\
\hline Residing community & $1.09(0.94,1.27)$ & $1.10(0.90,1.34)$ & $1.11(0.87,1.40)$ & $1.11(0.95,1.30)$ & $0.99(0.55,1.80)$ \\
\hline$p$-value of suest test & & \multicolumn{2}{|c|}{0.97} & \multicolumn{2}{|c|}{0.70} \\
\hline Residing city & $1.02(0.89,1.17)$ & $0.89(0.74,1.07)$ & $1.28 *(1.02,1.61)$ & $1.02(0.88,1.18)$ & $0.97(0.52,1.79)$ \\
\hline$p$-value of suest test & & \multicolumn{2}{|c|}{$0.01 *$} & \multicolumn{2}{|c|}{0.88} \\
\hline
\end{tabular}

Notes: All ordered logistic regressions controlled for covariates listed in Table 2. 95\% confidence intervals for estimated odds ratios are in parentheses. Regression coefficients were compared across subgroups using seemingly unrelated estimation test. ${ }^{*} 0.01 \leq p<0.05,{ }^{* *} 0.001 \leq p<0.01$, and ${ }^{* * *} p<0.001$.

Table 2 also reports the estimated associations between individual-level covariates and life satisfaction. Being an ethnic minority, married, in good or excellent self-rated health, of high school or higher education level, of higher absolute income, and a government employee were found to be positively associated with life satisfaction. In contrast, age, sex, number of children in the household, 
being religious, and resident registration status were not found to be associated with respondents' life satisfaction ( $p$-values $>0.05)$.

\section{Discussion}

The study assessed the cross-sectional relationship between four dimensions of relative income and life satisfaction among Chinese adults. Adjusting for age, sex, ethnicity, marital status, number of children in the household, self-rated health, education level, absolute annual income, job type, religion, and resident registration status, respondents' life satisfaction was found to be positively associated with relative income in comparison to their relatives and friends but not associated with relative income in comparison to their residing community and city. Subgroup analyses replicated the findings among male respondents and respondents with good or excellent self-rated health. In contrast, female respondents' life satisfaction was found to be positively associated with relative income in comparison to their residing city, but not associated with relative income in comparison to their relatives, friends, and residing community. Life satisfaction among those with poor or fair self-rated health was not found to be associated with any of the four dimensions of relative income.

Our findings, in general, confirm the important role relative income plays in people's life satisfaction. And the effect of relative income of relatives, friends, residing community, and residing city on life satisfaction were found to be distinct. These findings suggest the importance of within-group comparison in shaping individuals' life satisfaction in segregated societies such as China [45]. One potential explanation is that subjective within-group comparison involves substantial cognitive judgment on the reference group and subjective assessment on relative status, and some social reference groups that have frequent social contact with individuals, such as relatives and friends, may be more significant.

Some previous studies have shown similar results in other regions or different social groups. A previous study in 28 post-transition countries found that the adverse impact on subjective well-being and life satisfaction was primarily linked to the underachievement in the standard of living and underperformance relative to one's former schoolmates or colleagues, rather than one's self-ranking on the social ladder [38]. However, the study did not extend the comparison to other relevant groups, such as those living in the same community or city. Using large-scale European social survey data, a study on relative income in relation to subjective well-being reported that workplace colleagues were the most frequently cited reference group, and those who compared to colleagues tended to be happier than those who compared to other benchmarks [39]. None of the above studies assessed the potential mediating and/or moderating effect of certain personal characteristics.

However, our findings tend to deviate from a study based on national survey data in China [40]. Subjective assessments of relative income were found to be positively associated with psychosocial health regardless of the reference groups chosen (i.e., relatives, classmates, coworkers, neighbors, city, or province). Moreover, their results indicated that relative income in comparison to urban participants' former classmates and relatives was more important than their coworkers. However, instead of focusing on classmates and coworkers, we examined relative income in comparison to participants' friends. The different findings on relative income in comparison to participants' residing community (or neighborhood) and city may stem from three factors. First, the assessment time point is different. The previous study collected data in 2004, whereas we employed data in 2016. Second, the sample coverage is different. The previous study chose 31 provinces in China, whereas we selected two of China's largest cities, Beijing and Chengdu. Third, the dependent variables are different. The previous study adopted self-reported health status and an index of psychosocial health as the primary outcomes, whereas we focused on life satisfaction.

This new data point indicates the relationship between relative income and life satisfaction could vary by gender and health status. Since most regression coefficients across subgroups did not differ, we mainly focused on the differences with statistical significance. Male participants' life satisfaction was positively associated with relative income in comparison to their relatives and friends but not 
in comparison to their residing community and city, which indicates that the main source of "peer pressure" among men may come from their proximal rather than distal social network. Previous work suggests that people's life satisfaction is likely to be affected by individuals with resembling characteristics and opportunities in life, such as their friends, co-resident spouses, and next-door neighbors [24]. Those peer effects tend to be attenuated over time and/or through geographical separation [46]. Female respondents' life satisfaction was positively associated with relative income in comparison to their residing city but not in comparison to their relatives, friends, and residing community. This finding coincides with a recent study that documented life satisfaction to be correlated with relative income among men but not women [47]. This gender difference could be partially due to the conventional gender roles in Chinese society. In China, women often play a major role as caregiver of the home and family [41]. Improving or maintaining high-quality living conditions of the family might serve as a priority for caregivers [48], whereas the cost of living is mostly determined outside their immediate social environment but at the city level $[49,50]$. Health tends to be a key moderator in the relationship between relative income and life satisfaction [51]. Life satisfaction was associated with relative income among healthy respondents but not their counterparts with poor or fair health status. This finding is consistent with previous research that documented the central role of health and disease in defining subjective well-being [42].

A potential impact of the results on public policies is, aiming at the improvement of life satisfaction in the general population, developing countries, such as China, should focus on income redistribution to reduce relative income inequality. However, the relative income in comparison to some social groups that have frequent social contact with individuals is hard to regulate through public policy. So focusing on economic growth as a way to increase people's absolute income may be a more efficient way to improve individuals' life satisfaction in China. In addition, gender and health disparities may need to be taken into account in public policy formulation.

Several limitations of this study should be noted. The CGPiS was conducted in two major cities in China so that the study findings were unlikely to be generalizable to the Chinese adult population nationwide. The "effect" of one income comparison was computed under the assumption of "fixed" income and "fixed" other income comparisons. Relative income was self-reported and subject to measurement error and social desirability bias [52]. Life satisfaction was measured by a single question item, which did not differentiate distinct domains of life. The subsample of respondents in poor or fair health was rather small $(n=112)$ so that the relevant regression estimates should be interpreted with caution. The point estimates were very similar to those of the other subsamples, only the confidence intervals were wider, due to the very low number of observations. Due to the lack of experimental design, findings from this observational study only indicate associations but preclude any casual interpretations. Relative income in comparison to respondents' residing community city could be more difficult to evaluate for respondents. Therefore, the variables may suffer from a larger measurement error than their counterparts in comparison to respondents' relatives and friends. Ceteris paribus, the estimated associations between relative income in comparison to respondents' residing community/city and life satisfaction could be smaller (i.e., more biased towards the null) than the estimated associations between relative income in comparison to respondents' relatives/friends and life satisfaction.

In conclusion, this study assessed the relationship between relative income and life satisfaction among Chinese adults. Among male respondents and respondents with good or excellent self-rated health, life satisfaction was found to be positively associated with relative income in comparison to their relatives and friends but not associated with relative income in comparison to their residing community and city. Among female participants, life satisfaction was found to be positively associated with relative income in comparison to their residing city, but not associated with relative income in comparison to their relatives, friends, and residing community. Among respondents with poor or fair self-rated health, life satisfaction was not found to be associated with any of the four relative income dimensions. This study has design and measurement limitations. Future studies adopting a 
longitudinal or experimental design are warranted to advance our understanding of the relationship between relative income and life satisfaction among Chinese adults.

Author Contributions: Conceptualization, C.G.; methodology, Y.Q.; formal analysis, Y.Q.; resources, C.G.; data curation, Y.Q.; writing — original draft preparation, Y.Q.; writing—review and editing, R.A. and Y.Q.; supervision, C.G.; project administration, C.G.; funding acquisition, C.G.

Funding: The APC was funded by School of Economics and Resource Management, Beijing Normal University.

Conflicts of Interest: The authors declare no conflict of interest.

\section{References}

1. Medvedev, O.N.; Landhuis, C.E. Exploring constructs of well-being, happiness and quality of life. Peerj 2018, 6, e4903. [CrossRef] [PubMed]

2. Adler, M.D.; Fleurbaey, M. The Oxford Handbook of Well-Being and Public Policy; Oxford University Press: Oxford, UK, 2016.

3. Clapham, D.; Foye, C.; Christian, J. The concept of subjective well-being in housing research. Hous. Theory Soc. 2017, 35, 261-280. [CrossRef]

4. Hurd, M.D.; Rohwedder, S.; Tassot, C. The impact of employment transitions on subjective well-being evidence from the great recession and its aftermath. Fertil. Steril. 2015, 102, 75-81. [CrossRef]

5. Bergsma, A. Transhumanism and the wisdom of old genes is neurotechnology as source of future happiness? J. Happiness Stud. 2000, 1, 401-417. [CrossRef]

6. Hong, S.M.; Giannakopoulos, E. Effects of age, sex, and university status on life-satisfaction. Psychol. Rep. 1994, 74, 99. [CrossRef] [PubMed]

7. Schimmack, U.; Oishi, S.; Furr, R.M.; Funder, D.C. Personality and life satisfaction: A facet-level analysis. Personal. Soc. Psychol. Bull. 2004, 30, 1062-1075. [CrossRef]

8. Breslow, L. A quantitative approach to the world health organization definition of health: Physical, mental and social well-being. Int. J. Epidemiol. 1972, 1, 347-355. [CrossRef]

9. Berger, E.M. Happy working mothers? Investigating the effect of maternal employment on life satisfaction. Economica 2013, 80, 23-43. [CrossRef]

10. Dubrovina, N.; Siwiec, A.; Ornowski, M. Impact of socio-demographic factors and health state on indicator of life satisfaction of population in Poland. Procedia Econ. Financ. 2012, 1, 128-137. [CrossRef]

11. Herman, K.M.; Hopman, W.M.; Rosenberg, M.W. Self-rated health and life satisfaction among Canadian adults: Associations of perceived weight status versus BMI. Qual. Life Res. 2013, 22, 2707-2708. [CrossRef]

12. Kim, J.H.; Yoo, K.B.; Park, E.C.; Lee, S.G.; Kim, T.H. Combined effects of education level and perceived social class on self-rated health and life satisfaction: Results of Korean labor and income panel study wave 8-wave 15. Health Qual. Life Outcomes 2015, 13, 1-10. [CrossRef] [PubMed]

13. Wolbring, T.; Keuschnigg, M.; Negele, E. Needs, comparisons, and adaptation: The importance of relative income for life satisfaction. Eur. Sociol. Rev. 2013, 29, 86-104. [CrossRef]

14. Yuen, Y.M.; Lee, M.; Leung, C.S.S. Religious belief and its association with life satisfaction of adolescents in Hong Kong. J. Beliefs Values 2016, 37, 1-11. [CrossRef]

15. Zou, X.; Ingram, P.; Higgins, E.T. Social networks and life satisfaction: The interplay of network density and regulatory focus. Motiv. Emot. 2015, 39, 693-713. [CrossRef] [PubMed]

16. Duesenberry, J.S. Income, Saving and the Theory of Consumer Behavior; Harvard University Press: Cambridge, UK, 1949.

17. Easterlin, R.A.; Morgan, R.; Switek, M.; Wang, F. China's life satisfaction, 1990-2010. Proc. Natl. Acad. Sci. USA 2012, 109, 9775-9780. [CrossRef]

18. Proto, E.; Rustichini, A. A reassessment of the relationship between GDP and life satisfaction. PLoS ONE 2013, 8, e79358. [CrossRef]

19. Easterlin, R.A. Does economic growth improve the human lot? Some empirical evidence. Nations Househ. Econ. Growth 1974, 89-125. [CrossRef]

20. Boodoo, M.U.; Gomez, R.; Gunderson, M. Relative income, absolute income and the life satisfaction of older adults: Do retirees differ from the non-retired? Ind. Relat. J. 2014, 45, 281-299. [CrossRef] 
21. Conchita, D.; Frick, J.R. Income satisfaction and relative deprivation: An empirical link. Soc. Indic. Res. 2007, 81, 497-519. [CrossRef]

22. Distante., R. Subjective well-being, income and relative concerns in the UK. Soc. Indic. Res. 2013, 113, 81-105. [CrossRef]

23. Hodkinson, B.; Visser, M. Effects of objective and subjective income comparisons on subjective wellbeing. Soc. Indic. Res. 2016, 128, 361-389. [CrossRef]

24. Kuegler, A. A Curse of Comparison? Evidence on Reference Groups for Relative Income Concerns. World Bank Policy Research Working Paper Series. 2009. Available online: https://ssrn.com/abstract=1331879 (accessed on 21 April 2019).

25. Georgellis, Y.; Tsitsianis, N.; Yin, Y.P. Personal values as mitigating factors in the link between income and life satisfaction: Evidence from the European social survey. Soc. Indic. Res. 2009, 91, 329-344. [CrossRef]

26. Antinyan, A. Reference group income and subjective well-being: Empirical evidence from low-income transition economies. Soc. Indic. Res. 2015, 127, 1333-1348. [CrossRef]

27. Clark, A.E.; Senik, C.; Yamada, K. The Joneses in Japan: Income Comparisons and Financial Satisfaction. ISER Discuss. Pap. 2013, 866. [CrossRef]

28. Dumludag, D.; Gokdemir, O.; Vendrik, M. Relative Income and Life Satisfaction of Turkish Immigrants: The Impact of a Collectivistic Culture. IZA Discuss. Pap. 2015, 9282. Available online: https://ssrn.com/ abstract $=2655322$ (accessed on 21 April 2019).

29. Gokdemir, O.; Dumludag, D. Life satisfaction among Turkish and Moroccan immigrants in the Netherlands: The role of absolute and relative income. Soc. Indic. Res. 2012, 106, 407-417. [CrossRef]

30. Hudson, E. Does relative material wealth matter for child and adolescent life satisfaction? J. Socio-Econ. 2013, 46, 38-47. [CrossRef]

31. Yu, H. The impact of self-perceived relative income on life satisfaction: Evidence from British panel data. Soc. Sci. Electron. Publ. 2017. [CrossRef]

32. Ferrer-I-Carbonell, A. Income and well-being: An empirical analysis of the comparison income effect. J. Public Econ. 2005, 89, 997-1019. [CrossRef]

33. Luttmer, E.F.P. Neighbors as negatives: Relative earnings and well-being. Q. J. Econ. 2005, 120, $963-1002$. [CrossRef]

34. Helliwell, J.F.; Huang, H. How's the job? Well-being and social capital in the workplace. ILR Rev. 2010, 63, 205-227. [CrossRef]

35. Mcbride, M. Relative-income effects on subjective well-being in the cross-section. J. Econ. Behav. Organ. 2001, 45, 251-278. [CrossRef]

36. Brown, G.D.A.; Gardner, J.; Oswald, A.J.; Qian, J. Does wage rank affect employees' wellbeing? Soc. Sci. Electron. Publ. 2010, 47, 355-389. [CrossRef]

37. Senik, C. When information dominates comparison: Learning from Russian subjective panel data. Soc. Sci. Electron. Publ. 2002, 88, 2099-2123. [CrossRef]

38. Senik, C. Direct evidence on income comparisons and their welfare effects. J. Econ. Behav. Organ. 2009, 72, 408-424. [CrossRef]

39. Clark, A.E.; Senik, C. Who compares to whom? The anatomy of income comparisons in Europe. Econ. J. 2010, 120, 573-594. [CrossRef]

40. Mangyo, E.; Park, A. Relative deprivation and health: Which reference groups matter? J. Hum. Resour. 2011, 46, 459-481. [CrossRef]

41. Li, Y. On intellectual women's difficult choices between career and family during the period of the Republic of China. Soc. Sci. Beijing 2016, 6, 112-118. (In Chinese)

42. Okun, M.A.; George, L.K. Physician- and self-ratings of health, neuroticism and subjective well-being among men and women. Personal. Individ. Differ. 1984, 5, 533-539. [CrossRef]

43. Smith, H.J.; Pettigrew, T.F. Advances in relative deprivation theory and research. Soc. Justice Res. 2015, 28, 1-6. [CrossRef]

44. Hogg, M.A. Social Identity Theory. In Contemporary Social Theories; Burke, P., Ed.; Stanford University Press: Palo Alta, CA, USA, 2016; pp. 111-136.

45. Shu, C.; Jia, W. Less advantaged, more optimistic? Subjective well-being among rural, migrant and urban populations in contemporary china. China Econ. Rev. 2018, 52, 95-110. [CrossRef] 
46. Fowler, J.H. Dynamic spread of happiness in a large social network: Longitudinal analysis of the Framingham heart study social network. Br. Med. J. 2009, 338, 23-27. [CrossRef]

47. Mayraz, G.; Wagner, G.G.; Schupp, J. Life satisfaction and relative income: Perceptions and evidence. LSE Res. Online Doc. Econ. 2009, 7. [CrossRef]

48. Gellman, M.D.; Turner, J.R. Family Caretaker; Springer: New York, NY, USA, 2013.

49. Frank, R.H. Luxury fever: Why money fails to satisfy in an era of excess. Evol. Hum. Behav. 2001, 22, 71-74. [CrossRef]

50. Frank, R.H. Positional externalities cause large and preventable welfare losses. Am. Econ. Rev. 2005, 95, 137-141. [CrossRef]

51. Kahneman, D.; Deaton, A. High income improves evaluation of life but not emotional well-being. Proc. Natl. Acad. Sci. USA 2010, 107, 16489-16493. [CrossRef]

52. Fisher, R.J.; Katz, J.E. Social-desirability bias and the validity of self-reported values. Soc. Sci. Electron. Publ. 2000, 17, 105-120. [CrossRef]

(C) 2019 by the authors. Licensee MDPI, Basel, Switzerland. This article is an open access article distributed under the terms and conditions of the Creative Commons Attribution (CC BY) license (http://creativecommons.org/licenses/by/4.0/). 